\title{
Identification of the NADH-oxidase gene in Trichomonas vaginalis
}

\author{
Aline Lamien-Meda ${ }^{1} \cdot$ David Leitsch $^{1}$ (1)
}

Received: 8 October 2019 / Accepted: 4 December 2019/Published online: 18 December 2019

(C) The Author(s) 2019

\begin{abstract}
The microaerophilic human parasite Trichomonas vaginalis causes infections in the urogenital tract and is one of the most often sexually transmitted pathogens worldwide. Due to its anaerobic metabolism, it has to quickly remove intracellular oxygen in order to avoid deactivation of essential metabolic enzymes such as oxygen-sensitive pyruvate:ferredoxin oxidoreductase (PFOR). Two major enzyme activities which are responsible for the removal, i.e. reduction, of molecular oxygen have been identified in T. vaginalis flavin reductase, formerly designated NADPH oxidase, which indirectly reduces oxygen to hydrogen peroxide via flavin mononucleotide (FMN), and NADH oxidase which reduces oxygen to water. Flavin reductase has been identified and characterized at the gene level as well as enzymatically, but NADH oxidase has so far only been characterized enzymatically with enzyme isolated from $T$. vaginalis cell extracts. In this study, we identified NADH oxidase by mass spectrometry after isolation of the enzyme from gel bands positively staining for NADH oxidase activity. In strain C1 (ATCC 30001) which is known to lack NADH oxidase activity completely, the NADH oxidase gene has a deletion at position 1540 of the open reading frame leading to a frame shift and, as a consequence, to premature termination of the encoded polypeptide.
\end{abstract}

Keywords Trichomonas vaginalis $\cdot$ Anaerobiosis $\cdot$ Oxygen scavenging $\cdot$ NADH oxidase

\section{Introduction}

The microaerophilic parasite Trichomonas vaginalis is one of the most prevalent sexually transmitted pathogens worldwide, causing hundreds of millions of infections every year (Leitsch, 2016). The parasite colonizes the urogenital tract and causes urethritis, vaginitis and cervicitis. Moreover, T. vaginalis can cause adverse pregnancy outcomes (Silver et al., 2014) and facilitates infection with HIV (Masha et al., 2019). Due to its anaerobic metabolism, $T$. vaginalis has to effectively remove intracellular oxygen in order to prevent the deactivation of essential enzymes such as pyruvate:ferredoxin oxidoreductase

Handling Editor: Julia Walochnik

Electronic supplementary material The online version of this article (https://doi.org/10.1007/s00436-019-06572-8) contains supplementary material, which is available to authorized users.

David Leitsch

david.leitsch@meduniwien.ac.at

1 Institute for Specific Prophylaxis and Tropical Medicine Center for Pathophysiology, Infectiology, and Immunology, Medical University of Vienna, Kinderspitalgasse 15, A-1090 Vienna, Austria
(PFOR) and hydrogenase (Lloyd and Kristensen, 1985). Two major oxygen scavenging activities have been identified which both reside in the cytoplasm (Tanabe 1979; Linstead and Bradley, 1988): NADPH oxidase and NADH oxidase. The former reduces flavin mononucleotide (FMN) and other flavins through oxidation of NADPH (Linstead and Bradley 1988; Leitsch et al., 2014). Reduced FMN, in turn, rapidly reacts with molecular oxygen to form hydrogen peroxide (Chapman et al., 1999; Leitsch et al., 2014). The latter reduces molecular oxygen to water (Tanabe, 1979) by harnessing electrons derived from NADH. The gene for NADPH oxidase, which has been renamed to flavin reductase, was recently identified and characterized (Leitsch et al., 2014). Importantly, flavin reductase activity is decreased or absent in metronidazoleresistant $T$. vaginalis isolates (Leitsch et al., 2012, 2014). This leads to elevated intracellular oxygen concentrations and, as a consequence, to a decreased reduction of metronidazole, a prerequisite for metronidazole toxicity (reviewed in Leitsch, 2019). In contrast to flavin reductase, NADH oxidase has so far only been characterized at the protein level using enzyme isolated from $T$. vaginalis extracts (Linstead and Bradley, 1988). It was described to be monomeric and $98 \mathrm{kDa}$ in size and to be highly vulnerable to atmospheric oxygen 
concentrations and to hydrogen peroxide. Recently, it was also shown that NADH oxidase activity is sharply decreased in metronidazole-treated T. vaginalis (Leitsch et al., 2014), rendering flavin reductase the only active oxygen scavenging enzyme active in the presence of oxygen. This might explain the irrelevance of NADH oxidase for metronidazole resistance (Rasoloson et al., 2001). Interestingly, one well-studied $T$. vaginalis strain C1 (ATCC 30001) is devoid of NADH oxidase activity (Müller and Gorrell, 1983), indicating that NADH oxidase is not strictly essential for survival of the parasite in vivo.

The aim of this study was to identify the NADH oxidase gene in order to facilitate further, more directed research on this unusual enzyme.

\section{Materials and methods}

\section{Chemicals}

Nitroblue tetrazolium (NBT) was purchased from Sigma.

\section{Cell culture}

Trichomonas vaginalis strains C1 (ATCC 30001) and G3 (PRA-98) were grown in trypticase, yeast extract, maltose medium (TYM) (Diamond, 1957) and sub-cultured every day or every second day.

\section{Visualization of NADH oxidase activity by in-gel nitroblue tetrazolium blue (NBT) staining}

Trichomonas cell extracts were prepared, and native gel electrophoresis was performed, respectively, as described (Leitsch et al., 2014). Briefly, after harvest of cells and washing of cells in $1 \times$ PBS $(800 \times \mathrm{g}, 5 \mathrm{~min})$, cells were taken up in $100 \mathrm{mM}$ Tris pH 7.5 buffer and lysed in a Dounce homogenizer. Insoluble components were removed by centrifuging at $20,000 \times \mathrm{g}$ for $10 \mathrm{~min}\left(4^{\circ} \mathrm{C}\right)$. Resulting supernatants were loaded on native polyacrylamide gels lacking SDS. NBT staining was also performed as described before (Leitsch et al., 2014), but the assay buffer in which the gels were immersed for staining contained NADH instead of NADPH (100 mM Tris $\mathrm{pH} 7.5,0.5 \mathrm{mM} \mathrm{NAPH}$, and $0.2 \% \mathrm{NBT}$ ). After staining, gels were scanned and evaluated.

\section{Mass spectrometry of excised bands}

The upper gel band was excised and analysed as described (Leitsch et al., 2014). Briefly, proteins in gel bands were digested with trypsin and subsequently analysed by reversed phase LC-ESI ion trap tandem mass spectrometry using an UltiMate 3000 UHPLC system (Dionex, part of Thermo Fisher) coupled to an amaZon speed ETD ion trap (Bruker
Daltonics, Bremen, Germany). MS/MS spectra were analysed with Data Analysis 4.0 (Bruker Daltonics) and searched against the NCBI protein database (Version 28/08/2011, containing 15,148,518 sequences) using the in-house Mascot Server 2.3 (Matrix Science, UK) and ProteinScape 3.1 (Bruker Daltonics, Bremen, Germany). The same search parameters as given before (Leitsch et al., 2014) were applied. All analyses were performed in duplicate.

\section{Cloning of the NADH oxidase gene into the pET-17b vector}

The NADH oxidase gene was amplified by PCR from genomic DNA derived from $T$. vaginalis $\mathrm{G} 3$ cells using the following primers: TACGTACGCATATGCTTAAAATACAG CAGCTCACTGAAGA (forward) and TCATCCAG GGTACCTTAGTGATGGTGATGGTGATGGAAGATTTC AGCCATGATGC (reverse). The forward primer contains a flanking NdeI restriction site whereas the reverse primer encodes a $6 \times$ histidine tag for protein purification which was preceded by a KpnI restriction site. The PCR product was digested with NdeI and $\mathrm{KpnI}$ and ligated into the pET-17b vector.

\section{Expression of NADH oxidase in Escherichia coli BL21-AI}

The pET vector carrying the NADH oxidase gene was transformed into $E$. coli BL21-AITM (Thermo Fisher Scientific) for expression of NADH oxidase. Protein expression was started in $50 \mathrm{ml}$ batch cultures $(\mathrm{OD}=0.4-0.6)$ at $37^{\circ} \mathrm{C}$ upon addition of L-arabinose $(0.1 \%)$ and conducted without shaking to keep oxygen levels low. After expression, bacteria were lysed by grinding in a chilled mortar $\left(-20^{\circ} \mathrm{C}\right)$ with a pestle. Lysates were centrifuged at $20,000 \times \mathrm{g}$ at $4{ }^{\circ} \mathrm{C}$ to remove cell debris and chromosomal DNA, and resulting supernatants were loaded on Ni-NTA agarose columns (Qiagen). Recombinant NADH oxidase was purified from the extract via its $6 \times$ histidine tag.

\section{Sequencing of the NADH oxidase gene from strain C1}

Five overlapping fragments spanning the whole NADH oxidase gene were amplified from genomic DNA from strain C1 (for primers see Supplementary Table 1) and submitted for sequencing to Eurofins Genomics. This procedure was repeated once in order to ensure reproducibility.

\section{Results and discussion}

In analogy with previous work on flavin reductase (Leitsch et al., 2014), identification of NADH oxidase was attempted 


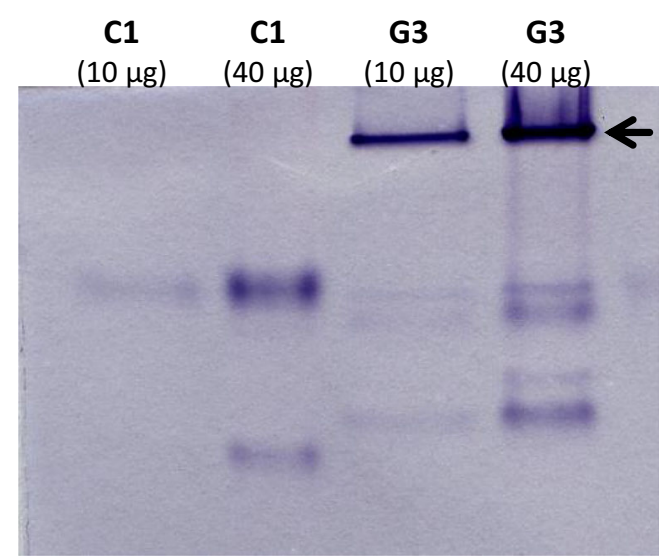

Fig. 1 In-gel staining with extracts of $\mathrm{G} 3$ and $\mathrm{C} 1$ after native PAGE using $\mathrm{NADH}$. The upper band is completely missing in $\mathrm{C} 1$ which is known to lack NADH oxidase activity

in native polyacrylamide gels upon staining with nitroblue tetrazolium (NBT). NBT is a yellowish tetrazolium compound forming blue formazan precipitates in gels and on membranes upon reduction, thereby allowing the identification of reductases in situ. Cell extracts of trophozoites from strain $\mathrm{C} 1$ and G3 were loaded, and gels were stained after gel electrophoresis using NADH as electron donor. Strain G3 was chosen because it is the genome strain (Carlton et al., 2007) whereas strain $\mathrm{C} 1$ is known to lack NADH oxidase activity, facilitating the identification of the enzyme through comparison of the staining patterns of G3 and C1. Indeed, G3 displayed a very strong and distinct stain in the upper part of the gel which was completely absent in C1 (Fig. 1). The band was excised and analysed by mass spectrometry. Only two proteins were found in the band to have a Mascot score above 90 (indicating 95\% confidence level) in two separate analyses: actin (XP_001301717 or TVAG_200190) and pyridine nucleotide-disulphide oxidoreductase family protein (XP_001315422 or TVAG_049830). Actin is one of the most abundant $T$. vaginalis proteins as visible on 2D-gels of $T$. vaginalis protein extracts (unpublished data) and therefore a likely contaminant across the gel. The second protein, however, has practically identical features to NADH oxidase as determined experimentally earlier, i.e. a theoretical size of $94,996 \mathrm{Da}$ (871 aa) and a pI of 5.75 as compared to approximately $98 \mathrm{kDa}$ and a pI of 5.2 (Linstead and Bradley, 1988). According to the NCBI database, the protein contains flavodoxin-like domain (aa 260-402), a rubredoxin-like domain (aa 436-469) and a pyridine nucleotide-disulphide oxidoreductase domain (aa 483-772) spanning a Rossmann fold typical of NAD $(\mathrm{P})(+)-$ binding proteins (aa 485-571). This structure is fully compatible with earlier observations on NADH oxidase, i.e. oxidation of NADH and reduction of oxygen (Tanabe 1979; Linstead and Bradley, 1988). The enzyme is a flavodiiron protein (FDP) which is a class of enzymes described to occur mainly in anaerobic organisms and to reduce oxygen and/or nitric oxide (Folgosa et al., 2018).

It was attempted to express the candidate NADH oxidase in E. coli. The recombinant enzyme could indeed be expressed in full length (Supplementary Fig. 1) but proved to be inactive, possibly to due to prolonged exposure to oxygen levels which exceed the enzyme's capacity. It is also possible that $E$. coli does not have the necessary capability to synthesize functional rubredoxin-containing proteins in large quantities. In order to obtain additional evidence that TVAG_049830 is indeed identical with NADH oxidase, the gene was amplified and sequenced from genomic DNA of strain $\mathrm{C} 1$ which lacks $\mathrm{NADH}$ oxidase. The gene was found to have a deletion at position 1540 (Supplementary Fig. 2) leading to a frame shift after aa 513. Premature termination of the polypeptide occurs 173 aa downstream of the frameshift mutation at position aa 684 . The frameshift mutation disrupts the NAD $(\mathrm{P})(+)$-binding domain (aa 485-571), most likely leading to inactivation of the enzyme. We, consequently, conclude TVAG_049830 is identical with NADH oxidase: (1) this enzyme is prominently present in the upper band in NBT in-gel stains when using extracts from G3 but absent when using extracts from $\mathrm{C} 1$ (Fig. 1), a strain which lacks NADH oxidase activity. (2) The particular structure of the gene regarding size, $\mathrm{pI}$ and domain composition is fully compatible with earlier observations (Linstead and Bradley, 1988), and (3) the gene is mutated in strain $\mathrm{C} 1$ leading to an inactive enzyme.

When performing a BLAST search with the TVAG_049830 protein sequence (XP_001315422), the enzyme displays $100 \%$ identity with "A-type flavoprotein" (CAI11388) and extensive identity with two additional proteins in $T$. vaginalis (Table 1). It also displays high similarity

Table 1 Sequence comparison of NADH oxidase (XP_001315422) using BLAST on the NCBI data base

\begin{tabular}{|c|c|c|c|c|c|}
\hline Entry & Name & Organism & $\begin{array}{l}\text { \% identity to } \\
\text { XP_001315422 }\end{array}$ & $\begin{array}{l}\% \text { similarity to } \\
\text { XP_001315422 }\end{array}$ & $\begin{array}{l}\text { Size } \\
\text { (aa) }\end{array}$ \\
\hline CAI11388 & A-type flavoprotein, partial & Trichomonas vaginalis & 100 & 100 & 852 \\
\hline XP_001317833 & Pyridine nucleotide-disulphide oxidoreductase family protein & Trichomonas vaginalis & 80 & 90 & 871 \\
\hline XP_001322980 & Pyridine nucleotide-disulphide oxidoreductase family protein & Trichomonas vaginalis & 79 & 89 & 871 \\
\hline ОНТ07162 & Pyridine nucleotide-disulphide oxidoreductase family protein & Tritrichomonas foetus & 55 & 71 & 910 \\
\hline WP_147633467 & MBL fold metallo-hydrolase & Turicibacter sanguinis & 52 & 69 & 870 \\
\hline
\end{tabular}


with a homologue in Tritrichomonas foetus (Table 1). TVAG_049830 was designated as "A-type flavoprotein" (a synonym for flavodiiron protein) in a study on lateral gene transfer from bacteria to trichomonads (Andersson et al., 2006). Indeed, the closest homologue of NADH oxidase outside the trichomonadids is a protein of almost identical size in Turicibacter sanguinis, a genus of intestinal bacteria in the phylum Firmicutes (Table 1). It is presently unclear if the two additional NADH oxidase homologues in $T$. vaginalis have a physiological role. It is important to note, however, that neither was identified in the upper band of the NBT ingel stains which suggests that the homologues are either not expressed or not active (or have different substrate specificity, respectively). Similar observations were made with flavin reductase (Leitsch et al., 2014) which has six further homologues in the genome of which only two show appreciable activity but with far lower affinity for FMN. In contrast, only one homologue of NADH oxidase exists in T. foetus (OHT07162). Thus, it is highly probable that NADH oxidase activity in $T$. foetus (Cerkasovová and Cerkasov, 1974) is exerted by this enzyme. Still, experimental evidence analogous to that as presented herein is needed for confirmation, because NADH oxidase activity can also be exerted by enzymes not related to TVAG_049830, such as NADH oxidase in Giardia lamblia (Brown et al., 1996). Finally, as soon as further trichomonadid genomes have been published, the occurrence of NADH oxidase amongst trichomonadids can be assessed more comprehensively.

Acknowledgements We thank Dr. Daniel Kolarich for the mass spectrometric analyses.

Funding information Open access funding provided by Medical University of Vienna. The work was funded by project P22546 from the Austrian Science Fund (FWF).

Open Access This article is licensed under a Creative Commons Attribution 4.0 International License, which permits use, sharing, adaptation, distribution and reproduction in any medium or format, as long as you give appropriate credit to the original author(s) and the source, provide a link to the Creative Commons licence, and indicate if changes were made. The images or other third party material in this article are included in the article's Creative Commons licence, unless indicated otherwise in a credit line to the material. If material is not included in the article's Creative Commons licence and your intended use is not permitted by statutory regulation or exceeds the permitted use, you will need to obtain permission directly from the copyright holder. To view a copy of this licence, visit http://creativecommons.org/licenses/by/4.0/.

\section{References}

Andersson JO, Hirt RP, Foster PG, Roger AJ (2006) Evolution of four gene families with patchy phylogenetic distributions: influx of genes into protist genomes. BMC Evol Biol 6:27
Brown DM, Upcroft JA, Upcroft P (1996) A H2O-producing NADH oxidase from the protozoan parasite Giardia duodenalis. Eur J Biochem 241:155-161

Carlton JM, Hirt RP, Silva JC, Delcher AL, Schatz M, Zhao Q, Wortman JR, Bidwell SL, Alsmark UC, Besteiro S, Sicheritz-Ponten T, Noel CJ, Dacks JB, Foster PG, Simillion C, van de Peer Y, MirandaSaavedra D, Barton GJ, Westrop GD, Müller S, Dessi D, Fiori PL, Ren Q, Paulsen I, Zhang H, Bastida-Corcuera FD, Simoes-Barbosa A, Brown MT, Hayes RD, Mukherjee M, Okumura CY, Schneider R, Smith AJ, Vanacova S, Villalvazo M, Haas BJ, Pertea M, Feldblyum TV, Utterback TR, Shu CL, Osoegawa K, de Jong PJ, Hrdy I, Horvathova L, Zubacova Z, Dolezal P, Malik SB, Logsdon JM Jr, Henze K, Gupta A, Wang CC, Dunne RL, Upcroft JA, Upcroft P, White O, Salzberg SL, Tang P, Chiu CH, Lee YS, Embley TM, Coombs GH, Mottram JC, Tachezy J, Fraser-Liggett CM, Johnson PJ (2007) Draft genome sequence of the sexually transmitted pathogen Trichomonas vaginalis. Science 315:207-212

Cerkasovová A, Cerkasov J (1974) Location of NADH-oxidase activity in fractions of Tritrichomonas foetus homogenate. Folia Parasitol (Praha) 21:193-203

Chapman A, Linstead DJ, Lloyd D (1999) Hydrogen peroxide is a product of oxygen consumption by Trichomonas vaginalis. J Biosci 24: 339-344

Diamond LS (1957) The establishment of various trichomonads of animals and man in axenic cultures. J Parasitol 3:488-490

Folgosa F, Martins MC, Teixeira M (2018) Diversity and complexity of flavodiiron NO/O2 reductases. FEMS Microbiol Lett 365(3)

Leitsch D, Drinić M, Duchêne M (2012) Downregulation of flavin reductase and alcohol dehydrogenase-1 (ADH-1) in metronidazoleresistant isolates of Trichomonas vaginalis. Mol Biochem Parasitol 183:177-183

Leitsch D, Janssen BD, Kolarich D, Johnson PJ, Duchêne M (2014) Trichomonas vaginalis flavin reductase 1 and its role in metronidazole resistance. Mol Microbiol 91:198-208

Leitsch D (2016) Recent advances in the Trichomonas field. F1000Res 2016 5. Pii: F1000 faculty Rev-162

Leitsch D (2019) A review on metronidazole: an old warhorse in antimicrobial chemotherapy. Parasitology 146:1167-1178

Linstead DJ, Bradley S (1988) The purification and properties of two soluble reduced nicotinamide: acceptor oxidoreductases from Trichomonas vaginalis. Mol Biochem Parasitol 27:125-133

Lloyd D, Kristensen B (1985) Metronidazole inhibition of hydrogen production in vivo in drug-sensitive and resistant strains of Trichomonas vaginalis. J Gen Microbiol 131:849-853

Masha SC, Cools P, Sanders EJ, Vaneechoutte M, Crucitti T (2019) Trichomonas vaginalis and HIV infection acquisition: a systematic review and meta-analysis. Sex Transm Infect 95:36-42

Müller M, Gorrell TE (1983) Metabolism and metronidazole uptake in Trichomonas vaginalis isolates with different metronidazole susceptibilities. Antimicrob Agents Chemother 24:667-673

Rasoloson D, Tomková E, Cammack R, Kulda J, Tachezy J (2001) Metronidazole-resistant strains of Trichomonas vaginalis display increased susceptibility to oxygen. Parasitology 123:45-56

Silver BJ, Guy RJ, Kaldor JM, Jamil MS, Rumbold AR (2014 Jun) (2014) Trichomonas vaginalis as a cause of perinatal morbidity: a systematic review and meta-analysis. Sex Transm Dis 41(6):369 376

Tanabe M (1979) Trichomonas vaginalis: NADH oxidase activity. Exp Parasitol 48:143-145

Publisher's note Springer Nature remains neutral with regard to jurisdictional claims in published maps and institutional affiliations. 